\title{
How to Face COVID-19 in Ophthalmology Practice
}

\author{
Xiaoting Pei ${ }^{1}$, Xinwei Jiao ${ }^{1}$, Dingli Lu ${ }^{1}$, Di Qi ${ }^{1}$, Shenzhen Huang ${ }^{1}$, Zhijie Li ${ }^{1}$ \\ ${ }^{1}$ Henan Eye Institute, Henan Eye Hospital and Henan Key Laboratory of Ophthalmology and Visual Science, Henan Provincial People's \\ Hospital, People's Hospital of Zhengzhou University, People's Hospital of Henan University, Zhengzhou City, China
}

Epub: May 29, 2020

\begin{abstract}
Background: The novel coronavirus pneumonia has attracted considerable attention from the international community. With the spread of outbreaks around the world, the WHO characterized COVID-19 as a pandemic.

Methods: Relevant studies in PubMed were searched from January 1, 2020 to April 12, 2020, using the following search strategy: ("novel coronavirus pneumonia" OR "severe acute respiratory syndrome coronavirus 2" OR "coronavirus disease 2019" OR "COVID-19" OR "novel coronavirus pneumonia") AND ("ophthalmology" OR "ophthalmologist" OR "eye" OR "conjunctiva" OR "conjunctivitis" OR "corneal" OR "keratitis").

Results: SARS-CoV-2 can spread through aerosol and is detected in tears of patients with COVID-19 infection. Notably, some infected patients had conjunctivitis, and conjunctivitis was the first symptom in some patients later diagnosed to have COVID-19 infection. This would increase the risk for ophthalmologists through inpatient consultations or regular clinical practice. When dealing with seemingly regular ophthalmic patients, the vigilance of ophthalmologists and associated staff tends to be reduced.

Conclusion: Ophthalmologists must continuously update their knowledge regarding COVID-19 and take effective measures to prevent COVID-19 transmission.

\section{KEY WORDS}

Severe Acute Respiratory Syndrome Coronavirus 2; Coronavirus Disease 2019; COVID-19; Ophthalmology; Ocular Surface; Conjunctivitis; Eye banking; Contact Precaution; Droplet Precaution; Ophthalmologist.

Copyright (c) 2020, Author(s). This is an open-access article distributed under the terms of the Creative Commons Attribution-Non Commercial 4.0 International License (http://creativecommons.org/licenses/by-nc/4.o/) which permits copy and redistribute the material just in noncommercial usages, provided the original work is properly cited.
\end{abstract}

Correspondence to: Professor Zhijie Li; Henan Eye Institute \& Henan Eye Hospital, Henan Provincial People's Hospital, Zhengzhou City, China, Tell: 0371-67120562, E-mail: zhijielee@vip.163.com

How to cite this article: Pei X, Jiao X, Lu D, Qi D, Huang S, Li Z. How to Face COVID-19 in Ophthalmology Practice. Med Hypothesis Discov Innov Ophthalmol. 2020; 9(3): 164-171.

\section{INTRODUCTION}

The outbreak of a novel coronavirus (CoV) in Wuhan City, Hubei Province, China, has become an international public-health emergency [1]. On February 11, 2020, the International Committee of Viral Taxonomy gave the name of severe acute respiratory syndrome coronavirus 2 (SARS-CoV-2), and the pneumonia it causes as coronavirus disease 2019 (COVID-19) by the World Health Organization (WHO) [2]. Up to April 12, 2020, the number of confirmed patients had reached 1.70 million worldwide, and the total number of deaths was 105,952. The infection was spread from China to the United States of America (the US). The number of new patients outside China far exceeded those reported inside China, especially in the US, Spain and Italy [3]. Finally, the WHO characterized COVID-19 as a pandemic on March 11 [1]. SARS-CoV-2 is a new type of betacoronavirus, it is heat and ultraviolet sensitive and can be inactivated after $30 \mathrm{~min}$ at $56^{\circ} \mathrm{C}$. Besides, $75 \%$ ethanol, chlorine-containing disinfectant, ether, peracetic acid, and chloroform can deactivate the virus. SARS-CoV-2 is believed to be homologous with a bat coronavirus, and some studies suggest that pangolins and minks may be intermediate 
virus hosts [4, 5]. The primary source of epidemic transmission is the infected patient; asymptomatic patients also contribute but are not the primary infection source [6-8]. A recent report showed that some patients are detected to have positive results even after 8 days of symptom relief [9]. The main transmission routes include respiratory droplets and contact with skin or body fluids/secretions containing the virus. WHO announced that SARS-CoV-2 can survive for eight hours in the air and spread through aerosol [10]. RNA of SARS-CoV-2 has also been found in stool samples of infected patients, which increase the possibility of transmission through the fecal/oral route [11]. Though a recent study detected viable SARS-CoV-2 in aerosols up to 3 hours postaerosolization [12], the non-ventilated environment for the experiment might not have reflected how viruses behave under real-life conditions. This study also found that the virus can survive for 4 hours on copper, 24 hours on cardboard, and 2-3 days on plastic or stainless steel [12], which indicated that handwashing and cleaning surfaces and materials contaminated by secretions of COVID-19 patients is important.

Infected patients often have fever, as well as respiratory symptoms, like cough and shortness of breath; some patients are presented with diarrhea shortly after infection. Pneumonia can also be a presentation in severe forms of the infection. Symptoms may occur as early as 214 days after exposure [13]. The average incubation period of SARS-CoV-2 is 5-7 days. More than $97 \%$ of patients develop symptoms within 11.5 days of exposure, which supports the current 14-day quarantine recommendations. Very few cases have lasted for 24 days [6].

COVID-19 is the third acute respiratory infectious disease caused by a cross-species coronavirus arisen in the past 20 years [7]. The first was severe acute respiratory syndrome (SARS) caused by the severe acute respiratory syndrome coronavirus (SARS-CoV), began in 2003 in Guangdong Province, China [14]. The second was the Middle East respiratory syndrome (MERS) caused by the Middle East respiratory syndrome coronavirus (MERS-CoV), which started in Saudi Arabia in 2012 [15]. During the SARS epidemic, about one-fifth of infected patients were medical workers. As of February 24, 2020, data from an official news source showed that 3,387 healthcare workers were infected with SARS-CoV-2 [16]. As of March 27, there were 6,205 and 9,444 medical workers diagnosed with COVID-19 in Italy and Spain, respectively [17]. More importantly, several recent studies have shown that the virus might invade the human body through the conjunctiva and cause conjunctivitis [18-21]. Although this phenomenon is currently uncommon in infected patients, it could increase the likelihood of infected patients visiting ophthalmologists $[22,23]$. To our knowledge, at least six ophthalmologists have been infected with COVID-19 in the original outbreak area of Wuhan City, China; three died, and the other three recovered (personal communication from Dr. Wei-Jing Yin, Director of the Editorial Office, Chinese Journal of Experimental Ophthalmology). Most ophthalmologists were not on the front lines of dealing with this outbreak in China, but they still had risks of infection and transmission for various reasons (e.g., consultation of infected patients, ophthalmic emergency in a hospital environment). Ophthalmologists should strictly follow measures to control the infection's spread when facing patients with infection or suspected infection for such reasons. This review paper aimed to provide background knowledge of COVID-19 and some suggestions for ophthalmologists and associated researchers on how to understand and deal with this problem.

\section{METHODS}

Relevant studies in PubMed were searched from January 1, 2020 to April 12, 2020, using the following search terms: ("novel coronavirus pneumonia" OR "severe acute respiratory syndrome coronavirus 2" OR "coronavirus disease 2019" OR "COVID-19" novel coronavirus pneumonia) AND ("ophthalmology" OR "ophthalmologist" OR "eye" OR "conjunctiva" OR "conjunctivitis" OR "corneal" OR "keratitis"). In addition, we searched and referenced the official website of the World Health Organization, Centers for Disease Control and Prevention, The American Academy of Ophthalmology, Eye Bank Association of America and National Health Commission of the People's Republic of China.

\section{RESULTS AND DISSCUSSION}

\section{COVID-19 AND OCULAR INFECTION}

CoVs belong to the category of respiratory viruses, which mainly infect the respiratory tract, and of which respiratory diseases are the main manifestations threatening public health. A study showed that some respiratory viruses also bind to the ocular surface and cause conjunctivitis in humans [24]. SARS-CoV is a respiratory virus that mainly infects the respiratory tract. It is primarily transmitted through direct or indirect contact with the respiratory-tract epithelium [14]. A study suggested that during the SARS epidemic, the risk of 
transmission from infected patients to medical staff increased due to lack of goggles [25]. SARS-CoV was detected in tears in three early-stage cases [26]. In animal models (including mice, cats, rats, and pigs), ocular diseases can be caused after SARS-CoV is inoculated in the eye, mouth, or nose [27-29]. However, some studies did not detect SARS-CoV in tears or conjunctival samples from SARS patients. No significant ocular abnormalities, or deterioration or acceleration of the original ocular disease, were found in SARS patients [30, 31]. Despite these inconsistent findings, the conjunctiva cannot be excluded as a potential invasive pathway for SARS-CoV-2. Like SARS-CoV, SARS-CoV-2 enters respiratory epithelial cells by binding to angiotensin-converting enzyme 2 (ACE2) on the cell surface through the spike (S) protein on the virus's surface and then replicates in the lung [32]. ACE2 messenger RNA (mRNA) and its enzyme are expressed in human eyes [33]. Further studies show that ACE2 is mainly expressed in the eye's posterior segment (including retinal nerve cells and retinal pigment epithelial cells) and exists in the aqueous humor [34, 35]. However, the characteristics of ACE2 expression in human corneal and conjunctival epithelial cells are not well-documented $[36,37]$. Recent studies found that some COVID-19 patients had conjunctivitis; in some patients, conjunctivitis was the first symptom [20,38]. Another study indicated that 2 of 27 COVID-19 patients had positive PCR results for SARS-CoV-2 in conjunctival-sac swab tests, but they did not have conjunctivitis [39]. Therefore, it is unclear whether the conjunctiva could be a locus of viral invasion and/or replication. It is crucial for healthcare workers to take various precautions according to the WHO guidelines that prevent the infection transmission [40, 41]. When in contact with patients diagnosed or suspected to have COVID-19, they should wear goggles and face masks to prevent possible transmission through facial skin, the nasal cavity, or the ocular surface.

\section{THE OPHTHALMOLOGIST'S ADAPTATION TO THE CURRENT COVID-19 PANDEMIC}

For Patients with Confirmed Diagnosis in the Hospital and/or Suspected Patients in Quarantine

In clinical practice, ophthalmologists might visit COVID-19 patients. The main reason is that some COVID-19 patients have ocular discomforts like dry eye and conjunctivitis, some develop ocular diseases (e.g., glaucoma) before infection that require an ophthalmologist visit, and occasionally an ocular emergency such as sudden vision loss $[38,42]$. When these situations happen, the following specific measures are recommended for better preventing primary transmission of SARS-CoV-2 to protect patients, families and medical staff [43].

\section{General Precautions}

To reduce the transmission between patients, ophthalmologists should practice the following common precautions [44]: 1) Handwashing: Wash hands before and after contact with infected patients. 2) Wearing gloves: Avoid contacting patient's blood, body fluids, secretions and personal possessions. 3) Medical waste should be put into a double-layer medical waste bag, and seal the bag with a gooseneck ties, and spray the waste bag by chlorine-containing disinfectant (1000 milligrams per liter).

\section{Droplet Transmission Precautions}

At present, SARS-CoV-2 main transmission modes are both droplet inhalation and contact. When the pathogen is transmitted from the infected or suspected infected person through the more than 5 micrometre droplets produced by coughing, sneezing, or speaking, the corresponding protection measures should be taken [41]. Specifically: 1) Wear N95 masks when working close to infected or suspected infected patients. 2) Try to reduce the transport of inpatients with SARS-CoV-2 infection as much as possible. Patients should wear masks during transfer. 3) Try to avoid working close by the patient, such as slit-lamp or fundoscopy examination.

\section{Contact Transmission Precautions}

Contact is the other main transmission route of SARS-CoV2. Most contact transmission occurs during clinical examination. In clinical practice, contact with the patient's eyes and tears is almost inevitable. Transmission of pathogens can occur when contaminated hands touch the face, the eyes, or open wounds. Main measures to be taken for ophthalmologists when visiting an infected or suspected patients are as follows [43, 45]: 1) Wear sterile gloves and a disposable gown before entering the infectious patient's ward, remove the gloves and the gown and wash hands with disinfectant immediately before leaving the patient's room, and ensure there is no further contact with the patient's environment and possessions to reduce the possibility of contamination. 2) Clean and disinfect equipment and properly dispose medical waste after the examination. This guideline considers the possibility that the virus could remain on various ophthalmic equipment (including slit lamp, Goldmann applanation tonometer, optical-coherence tomography (OCT), ophthalmic ultrasound equipment and trial frame) after an infected patient is examined. Thus, all ophthalmic equipment should be cleaned and disinfected (e.g., wiped with $75 \%$ ethanol or $3 \%$ hydrogen peroxide on a cotton 
ball) to ensure the safety for next patients. Equipment and instruments used by infected or suspected patients should be sterilized according to the Regulation of Disinfection Technique in Healthcare Settings [46].

\section{For Regular Outpatient Clinic}

Preliminary clinical research has shown that some COVID19 patients manifest conjunctivitis, which might be a symptom of this disease $[18,38]$. More importantly, an experimental study confirmed that rhesus macaques can be infected with SARS-CoV-2 via the conjunctiva with a relatively independent transmission route. Viral particles in tears and other eye secretions might enter respiratory tract through the nasolacrimal duct, or enter the digestive system after being swallowed [21, 35]. This means that ophthalmologists should take strict measures to prevent the possibility of transmission through the ocular surface. Therefore, they should pay close attention to the following issues [40, 47]: 1) travel history of patients to the US, Italy, Spain, Iran and other areas with high number of infected patients; or patients with family members that come back from these areas recently; 2 ) whether patients have respiratory symptoms; and 3) whether they have signs of conjunctivitis, such as conjunctival congestion and tearing. Patients who meet the above criteria should be examined for COVID-19.

The US and the Europe are now the outbreak centers. Ophthalmologists in these areas should take stricter measures to prevent the spread of infection. We recommend adoption of the following measures based on the WHO guidelines and recent published articles $[23,41]$ : (1) Pre-examination and triage area should be set up to perform preliminary screening of patients. (2) Avoid examinations as much as possible. When an examination is unavoidable, a transparent breath shield can be installed on the slit-lamp microscope to protect both healthcare workers and patients from droplet transmission occurring during the examination. (3) Directcontact examination of the ocular surface, as in a cornealperception examination or Schirmer's test for tear production, should be minimized as much as possible [48]. An indirect fundus ophthalmoscope or fundus angiography equipment could be used instead of a closecontact direct ophthalmoscope for patients who need a fundus examination. When necessary to measure the patient's intraocular pressure, a non-contact tonometer is recommended. Phenol red cotton thread or test strips for measuring tear secretion should be handled in strict accordance with dangerous medical-waste regulations. (4) Both doctors and patients should wear masks, and ophthalmologists should wear goggles. (5) Ophthalmologists and their associates should wash their hands between examinations of different patients to prevent cross-transmission. (6) For instruments (e.g., Goldmann applanation tonometer, gonioscope) directly contacting the ocular surface, "one patient, one disinfection" measures should be followed. Using a 70\% alcohol solution can effectively disinfect tonometer [47]. (7) Rooms, office furniture and other ophthalmic instruments where patients put their hands or faces, should be thoroughly disinfected with alcohol- and bleach-based disinfectants after each patient encounter [47]. Disinfectants specific to COVID-19 recommended by the US Centers for Disease Control and Prevention (CDC) are diluted household bleach, $>70 \%$ alcohol solutions, and common US Environmental Protection Agency (EPA)registered household disinfectants [49]. (8) When surfaces are cleaned and disinfected, disposable gloves should be worn and discarded after use.

\section{For Ophthalmic Operating Rooms during the Outbreak} The recommended measures are as follows [50]: (1) For nonemergency occasions, surgery in severely epidemic areas should be postponed. If it is necessary to perform an emergency operation, the suspected or confirmed infected patient should be scheduled as the last one, and the operation should be performed in an operating room with a negative-pressure environment and proper ventilation [51]. (2) Medical staff should wear medicalgrade protective masks and goggles. (3) During the pandemic, personnel flow during the operation should be reduced. (4) In the operating room, appropriate humidity $(<68 \%)$ and temperature control should be maintained. (5) A portable industrial-grade, high-efficiency particle barrier filter should be used to remove air pollutants quickly. (6) The following tertiary-prevention measures should be taken: (a) Respiratory protectors offering high ingress protection should be worn in the operating room, and (b) unnecessary personnel should be prohibited from entering the operating room.

\section{CONFIRMED AND SUSPECTED COVID-19 INFECTIONS ARE EXCLUSION CRITERIA FOR CORNEAL DONATION}

Keratoplasty is one of the most important measures for restoring corneal blindness. However, any organ or tissue transplantation has the risk of transmitting infectious diseases. Therefore, the eye bank system sets strict medical standards for screening potential donors [52]. During the 2003 SARS epidemic, one study found a large number of viral particles in many tissues and cell types, such as lymphocytes, monocytes, respiratory epithelial cells, intestinal mucosa, distal renal epithelial cells, neurons in the brain, and macrophages in different organs of infected patients [53]. Although, there is no evidence of 
SARS-CoV-2 virus particles in corneal tissue, and no clinical studies and/or case reports of transmission to recipients after corneal transplantation from donors with COVID-19, this possibility cannot be excluded. Given the similarities and high risk for transmission of SARS-CoV-2, the authors recommend the following [54]: (1) Corneal-transplant programs should be postponed during the outbreak, if possible. (2) Infected patients should not be used as potential donors even in emergency transplant situations. (3) Donors carrying the SARS-CoV-2 virus should be included in the eye bank medical-exclusion standards. (4) Before transplantation, it should be clear whether potential donors have a history of (a) confirmed or suspected COVID-19 infection and (b) respiratory-tract symptoms of suspected viral origin during the 14 days preceding death. Strict SARS-CoV-2 virus detection should be performed for donors. (5) Eye bank staff should obtain donors' recent travel history to epidemic areas and chest $X$-rays or computed-tomography (CT) image records to the greatest extent possible.

\section{COLLECTION, PROCESSING AND TRANSPORT OF OCULAR SPECIMENS}

For scientific research, diagnosis, and other special needs (e.g., detecting viruses or certain components in tears from confirmed or suspected infected persons), some eye samples or specimens must be collected. However, the results are usually affected by many factors, such as time, the surrounding collection environment, the amount of sample, the method of preservation, and the process of transport. It is critical to follow the established standards for the laboratory process [55]. In addition, considering the disease severity and its ease of transmission, all manipulations involving samples should follow strict biosafety procedures. Notably, when packing, mailing, and transporting specimens, the regulations for dangerous goods should be followed [56].

When detecting SARS-CoV-2 via reverse-transcription polymerase chain reaction (RT-PCR), special attention should be paid to the following points [55]: (1) use synthetic-fiber swabs instead of wooden swabs, which contain components such as calcium alginate that might inactivate some viruses and inhibit certain reactions during PCR testing; (2) prevent degradation of RNA in samples using RNAase-free water and dithiothreitol; (3) put the sample swab into a sterile tube containing 2-3 ml culture medium for virus transport; (4) change gloves when handling different patient samples to avoid crosscontamination; (5) perform all sample handling in a cold environment; and (6) store the sample at $-70^{\circ} \mathrm{C}$ as soon as possible and transport it in dry ice.
Table 1. A Summary of Main Recommendations Proposed to Face COVID-19 in Ophthalmology Practice.

How to Face COVID-19 in Ophthalmology Practice

General Precautions

1) Handwashing before and after contact with patients.

2) Wear gloves to avoid contacting body fluids and secretions.

3) Proper disposing of COVID-19 medical waste.

Droplet Transmission Precautions

1) Wear N95 masks when working close to patients.

2) Reduce transport of infected cases as much as possible.

3) Avoid working close as much as possible.

4) Patients should wear masks during transfer.

Contact Transmission Precautions

1) Wear sterile gloves and a disposable gown before entering the infectious ward.

2) Remove the gloves and gown and wash hands with disinfectant before leaving the patient's room.

3) Clean and disinfect all ophthalmic equipment (e.g., wiped with $75 \%$ ethanol or $3 \%$ hydrogen peroxide on a cotton ball) and properly dispose medical waste.

For Regular Outpatient Clinic

1) Take recent travel history of patients or their associates to high risk areas.

2) Ask for respiratory symptoms.

3) Ask for signs of conjunctivitis.

4) Set up triage area to perform preliminary screening.

5) Avoid close examinations as much as possible. Install breath shield on the slit-lamp.

6) Minimize direct-contact examination of the ocular surface as much as possible. Use indirect fundus ophthalmoscope or fundus angiography, instead.

7) Measure intraocular pressure using a non-contact tonometer.

8) Used test strips for measuring tear secretion should be handled with dangerous medical-waste regulations.

9) "one patient, one disinfection" measures should be followed.

10) Rooms, office furniture and ophthalmic instruments should be thoroughly disinfected.

11) When surfaces are disinfected, disposable gloves should be worn and discarded after use.

For Ophthalmic Operating Rooms

1) In nonemergency occasions, surgery should be postponed.

2) If surgery is emergency, the suspected or confirmed case should be scheduled as the last one, in a room with a negative-pressure environment and proper ventilation.

2) Medical staff should wear medical-grade protective masks and goggles.

3) Personnel flow during the operation should be reduced.

4) Appropriate humidity $(<68 \%)$ and temperature control should be maintained.

5) A portable industrial-grade, high-efficiency particle barrier filter should be used.

6) Respiratory protectors offering high ingress protection should be worn in the operating room, and unnecessary personnel should not enter the operating room. 


\section{CONCLUSION}

The main recommendations have been summarised in Table 1. Currently, the number of patients with COVID-19 infection is increasing worldwide. On the other hand, the virus could be potentially transmitted through the conjunctiva. Therefore, ophthalmologists should take strict measures in clinical practice to prevent the possibility of transmission through the ocular surface.

\section{ETHICAL DECLARATIONS}

Ethical Approval: This is a review article based on other published articles and no need for ethical approval.

Conflict of Interest: None.

\section{FUNDING}

This work was supported by the National Natural Science Foundation of China (Grant Nos. 81470603, 81770962) and the Ministry of Science and Technology of the People's Republic of China (Grant No. 2018YFC0114500). The funders had no role in study design, data collection and analysis, decision to publish, or preparation of the manuscript.

\section{ACKNOWLEDGMENTS}

We appreciate the National Natural Science Foundation of China and the Ministry of Science and Technology of the People's Republic of China to support this work.

\section{REFERENCES}

1. World Health Organization. WHO Director-General's opening remarks at the media briefing on COVID-19 2020 [updated 20 March 2020; cited 11 March 2020]. Available from: https://www.who.int/dg/speeches/detail/whodirector-general-s-opening-remarks-at-the-media-briefingon-covid-19---11-march-2020.

2. World Health Organization. Naming the coronavirus disease (COVID-19) and the virus that causes it 2020 [20 March 2020]. Available from: https://www.who.int/emergencies/diseases/novelcoronavirus-2019/technical-guidance/naming-thecoronavirus-disease-(covid-2019)-and-the-virus-thatcauses-it.

3. World Health Organization. Coronavirus disease 2019 (COVID-19) Situation Report - 832020 [19 April 2020]. Available from: https://www.who.int/docs/defaultsource/coronaviruse/situation-reports/20200412-sitrep-83covid-19.pdf?sfvrsn=697ce98d_4.
4. Lam $T$, Shum $M$, Zhu $H$, Tong $Y, N i X$, Liao $Y$, et al. Identifying SARS-CoV-2 related coronaviruses in Malayan pangolins. Nature. 2020. doi: 10.1038/s41586-020-2169-0

5. Zhou P, Yang XL, Wang XG, Hu B, Zhang L, Zhang W, et al. A pneumonia outbreak associated with a new coronavirus of probable bat origin. Nature. 2020;579(7798):270-3. doi: 10. 1038/s41586-020-2012-7 pmid: 32015507

6. National Health Commission of the People's Republic of China. Diagnosis and treatment of Novel coronavirus pneumonia (Trial implementation: version 6). [cited 10 April 2020]. Available from: http://www.nhc.gov.cn/xcs/fkdt/202002/54e1ad5c2aac45c 19eb541799bf637e9.shtml

7. Cohen J. The coronavirus seems unstoppable. What should the world do now? Science. 2020. doi: 10.1126/science. abb4604

8. Bai Y, Yao L, Wei T, Tian F, Jin DY, Chen L, et al. Presumed Asymptomatic Carrier Transmission of COVID-19. JAMA. 2020. doi: 10.1001/jama.2020.2565 pmid: 32083643

9. Chang, Mo G, Yuan X, Tao Y, Peng X, Wang FS, et al. Time Kinetics of Viral Clearance and Resolution of Symptoms in Novel Coronavirus Infection. Am J Respir Crit Care Med. 2020;201(9):1150-2. doi: 10.1164/rccm.202003-0524LE pmid: 32200654

10. World Health Organization. WHO considers 'airborne precautions' for medical staff after study shows coronavirus can survive in air [cited 29 March 2020]. Available from: https://www.cnbc.com/2020/03/16/who-considersairborne-precautions-for-medical-staff-after-study-showscoronavirus-can-survive-in-air.html.

11. Pan Y, Zhang D, Yang P, Poon L, Wang Q. Viral load of SARSCoV-2 in clinical samples. The Lancet Infectious Diseases. 2020;20(4):411-2. doi: 10.1016/s1473-3099(20)30113-4

12. van Doremalen N, Bushmaker T, Morris DH, Holbrook MG, Gamble A, Williamson BN, et al. Aerosol and Surface Stability of SARS-CoV-2 as Compared with SARS-CoV-1. N Engl J Med. 2020;382(16):1564-7. doi: 10.1056/NEJMc2004973 pmid: 32182409

13. Lauer SA, Grantz KH, Bi Q, Jones FK, Zheng Q, Meredith HR, et al. The Incubation Period of Coronavirus Disease 2019 (COVID-19) From Publicly Reported Confirmed Cases: Estimation and Application. Ann Intern Med. 2020. doi: 10.7326/M20-0504 pmid: 32150748

14. Peiris JS, Yuen KY, Osterhaus AD, Stohr K. The severe acute respiratory syndrome. N Engl J Med. 2003;349(25):2431-41. doi: 10.1056/NEJMra032498 pmid: 14681510

15. de Groot RJ, Baker SC, Baric RS, Brown CS, Drosten C, Enjuanes L, et al. Middle East respiratory syndrome coronavirus (MERS-CoV): announcement of the Coronavirus Study Group. J Virol. 2013;87(14):7790-2. doi: 10.1128/JVI.01244-13 pmid: 23678167

16. Over $90 \%$ of the medical staff infected with the virus come from Hubei [cited 29 March 2020]. Available from: http://www.chinanews.com/gn/2020/0224/9103094.shtml.

17. Prensa Latina. Covid-19 disease afflicts 9,000 health workers in Spain 2020 [cited 29 March 2020]. Available from: 
https://www.plenglish.com/index.php?o=rn\&id=53913\&SE $\mathrm{O}=$ covid-19-disease-afflicts-9000-health-workers-in-spain.

18. Lu C, Liu X, Jia Z. 2019-nCoV transmission through the ocular surface must not be ignored. The Lancet. 2020;395(10224). doi: 10.1016/s0140-6736(20)30313-5

19. Xia J, Tong J, Liu M, Shen Y, Guo D. Evaluation of coronavirus in tears and conjunctival secretions of patients with SARSCoV-2 infection. J Med Virol. 2020. doi: 10.1002/jmv.25725 pmid: 32100876

20. Chen L, Deng C, Chen X, Zhang X, Chen B, Yu H, et al. Ocular manifestations and clinical characteristics of 534 cases of COVID-19 in China:A cross-sectional study. medRxiv. 2020. doi: 10.1101/2020.03.12.20034678

21. Deng W, Bao L, Gao H, Xiang Z, Qu Y, Song Z, et al. Rhesus macaques can be effectively infected with SARS-CoV-2 via ocular conjunctival route. bioRxiv. 2020. doi: 10.1101/2020.03.13.990036

22. Reviglio VE, Osaba M, Reviglio V, Chiaradia P, Kuo IC, O'Brien TP. COVID-19 and Ophthalmology: A New Chapter in an Old Story. Med Hypothesis Discov Innov Ophthalmol. 2020;9(2):71-73.

23. Gharebaghi R, Desuatels J, Moshirfar M, Parvizi M, Daryabari SH, Heidary F. COVID-19: Preliminary Clinical Guidelines for Ophthalmology Practices. Med Hypothesis Discov Innov Ophthalmol. 2020;9(2):149-158.

24. Belser JA, Sun X, Creager HM, Johnson A, Ridenour C, Chen $\mathrm{LM}$, et al. Role of $\mathrm{H7}$ hemagglutinin in murine infectivity of influenza viruses following ocular inoculation. Virology. 2017;502:13-9. doi: 10.1016/j.virol.2016.12.008 pmid: 27960109

25. Raboud J, Shigayeva A, McGeer A, Bontovics E, Chapman M, Gravel D, et al. Risk factors for SARS transmission from patients requiring intubation: a multicentre investigation in Toronto, Canada. PLoS One. 2010;5(5):e10717. doi: 10.1371/journal.pone.0010717 pmid: 20502660

26. Bonn D. SARS virus in tears? The Lancet Infectious Diseases. 2004;4(8). doi: 10.1016/s1473-3099(04)01093-x

27. Martina BE, Haagmans BL, Kuiken $T$, Fouchier RA, Rimmelzwaan GF, Van Amerongen G, et al. Virology: SARS virus infection of cats and ferrets. Nature. 2003;425(6961):915. doi: 10.1038/425915a pmid: 14586458

28. Yang YL, Qin P, Wang B, Liu Y, Xu GH, Peng L, et al. Broad Cross-Species Infection of Cultured Cells by Bat HKU2Related Swine Acute Diarrhea Syndrome Coronavirus and Identification of Its Replication in Murine Dendritic Cells In Vivo Highlight Its Potential for Diverse Interspecies Transmission. J Virol. 2019;93(24). doi: 10.1128/JVI.0144819 pmid: 31554686

29. Wu D, Tu C, Xin C, Xuan H, Meng Q, Liu Y, et al. Civets are equally susceptible to experimental infection by two different severe acute respiratory syndrome coronavirus isolates. J Virol. 2005;79(4):2620-5. doi: 10.1128/JVI.79.4.2620-2625.2005 pmid: 15681462

30. Chan WM, Yuen KS, Fan DS, Lam DS, Chan PK, Sung JJ. Tears and conjunctival scrapings for coronavirus in patients with SARS. $\mathrm{Br} J$ Ophthalmol. 2004;88(7):968-9. doi: 10.1136/bjo.2003.039461 pmid: 15205249
31. Yuen KS, Chan WM, Fan DS, Chong KK, Sung JJ, Lam DS. Ocular screening in severe acute respiratory syndrome. Am J Ophthalmol. 2004;137(4):773-4. doi: 10.1016/j.ajo.2003.09.060 pmid: 15059730

32. Walls AC, Park YJ, Tortorici MA, Wall A, McGuire AT, Veesler D. Structure, Function, and Antigenicity of the SARS-CoV-2 Spike Glycoprotein. Cell. 2020;181(2):281-92 e6. doi: 10.1016/j.cell.2020.02.058 pmid: 32155444

33. Yin $\mathrm{X}$, Zhang J. Advance in research of beta coronavirus receptors on ocular surface. Chin J Exp Ophthalmol. 2020;38. doi: 10.3760/cma.j.cn115989-20200223-00098

34. Xie L, Zhou Q, Gao H, Shi W. Strengthening basic and clinical research on ocular infection caused by coronavirus. Chin J Ophthalmol. 2020;56. doi: 10.3760/cma.j.cn11214220200219-00087

35. Qing H, Li Z, Yang Z, Shi M, Huang Z, Song J, et al. The possibility of COVID-19 transmission from eye to nose. Acta Ophthalmol. 2020;98(3):e388. doi: 10.1111/aos.14412 pmid: 32189463

36. Holappa M, Vapaatalo H, Vaajanen A. Many Faces of Reninangiotensin System - Focus on Eye. Open Ophthalmol J. 2017;11:122-42. doi: 10.2174/1874364101711010122 pmid: 28761566

37. Choudhary R, Kapoor MS, Singh A, Bodakhe SH. Therapeutic targets of renin-angiotensin system in ocular disorders. J Curr Ophthalmol. 2017;29(1):7-16. doi: 10.1016/j.joco.2016.09.009 pmid: 28367520

38. Li XJ, Wang M, Dai J, Wang WJ, Yang YN, Jin W. Novel coronavirus disease with conjunctivitis and conjunctivitis as first symptom: Two cases report. Chin J Exp Ophthalmol. 2020;38. doi: 10.3760/cma.j.issn.115989-20200303-00133

39. Ye Y, Song Y, Yan M, Hu C, Chen X, Yu J. Novel coronavirus pneumonia combined with viral conjunctivitis: three cases report. Chin J Exp Ophthalmol. 2020;38. doi: 10.3760/cma.j.issn.2095-0160.2020.0006

40. World Health Organization. Coronavirus disease (COVID-19) travel advice [cited 20 March 2020]. Available from: https://www.who.int/emergencies/diseases/novelcoronavirus-2019/travel-advice.

41. World Health Organization. Coronavirus disease (COVID-19) advice for the public 2020 [cited 20 March 2020]. Available from: https://www.who.int/emergencies/diseases/novelcoronavirus-2019/advice-for-public.

42. Xu M, Zhang H, Niu X. A case of the coronavirus disease 2019 diagnosed by ophthalmology due to acute blepharitis and subconjunctival hemorrhage. Chin J Exp Ophthalmol. 2020;38. doi: 10.3760/cma.j.issn.115989-20200228-00121

43. Zhao M, Li X, Li M, Sun D. Prevention and control measures and workflow in clinical diagnosis and treatment practice of ophthalmology during the coronavirus disease 2019 epidemic. Chin J Exp Ophthalmol. 2020;38. doi: 10.3760/cma.j.issn.2095-0160.2020.0004

44. $\mathrm{Hu} \mathrm{VH}$, Watts $\mathrm{E}$, Burton $\mathrm{M}$, et al. Protecting yourself and your patients from COVID-19 in eye care. Community Eye Health. 2020;33(108):S1-S6.

45. Feng $T$, Wang $Y$, Nie $H$, Peng J. Current situation and suggestions for ophthalmic medical work in a non-COVID-19 
treatment hospital in later stages of epidemic. Chin J Exp Ophthalmol. 2020;38. doi: 10.3760/cma.j.issn.11598920200311-0016

46. National Health Commission of the People's Republic of China. Regulation of disinfection technique in healthcare settings 2020 [cited 17 February 2020]. Available from: http://www.nhc.gov.cn/wjw/s9496/201204/54510.shtml.

47. American Academy of Ophthalmology. Alert: Important coronavirus updates for ophthalmologists 2020 [cited 21 March 2020]. Available from: https://www.aao.org/headline/alert-importantcoronavirus-context.

48. Society of Public Health Ophthalmology. Chinese Preventive Medicine Association, Beijing Ophthalmological Society and Youth Committee of Beijing Ophthalmological Society. Suggestions from ophthalmic experts on eye protection during the novel coronavirus pneumonia epidemic. Chin J Ophthalmol. 2020;56. doi: 10.3760/cma.j.issn.04124081.2020.0002

49. United States Environmental Protection Agency. List N: Disinfectants for Use Against SARS-CoV-2 2020 [cited 21 March 2020]. Available from: https://www.epa.gov/pesticide-registration/list-ndisinfectants-use-against-sars-cov-2.

50. Zhou X, Qu J. 2019-nCoV and Eye, What We Know and What We Should Do. Chin J Optom Ophthalmol Vis Sci. 2020;22. doi: 10.3760/cma.j.issn.1674-845X.2020.0001
51. Xu Z, Zhou B. Air Distribution Design in Negative Pressure Isolation Ward. Dynamic Isolation Technologies in Negative Pressure Isolation Wards2017. p. 111-45. doi: 10.1007/978981-10-2923-3_4

52. Eye Bank Association of America. Medical Standards 2020 [19 February 2020]. Available from: https://restoresight.org/wpcontent/uploads/2017/07/Med-Standards-June-16-2017final.pdf.

53. Gu J, Taylor CR. Acute immunodeficiency, multiple organ injury, and the pathogenesis of SARS. Appl Immunohistochem Mol Morphol. 2003;11(4):281-2. doi: 10.1097/00129039-200312000-00001 pmid: 14663354

54. Pan L, Zeng J, Yang H. Challenges and countermeasures for organ donation during the SARS-CoV-2 epidemic: the experience of Sichuan Provincial People's Hospital. Intensive Care Med. 2020. doi: 10.1007/s00134-020-05978-8

55. Zheng M, Wu W, Chen W, Yu X, Shi Y, Qu J. Necessity and feasibility of viral RNA detection in specialist ophthalmic institute during the COVID-19 epidemic. Chin J Exp Ophthalmol. 2020;38. doi: 10.3760/cma.j.cn11598920200224-00105

56. National Health Commission of the People's Republic of China. Novel coronavirus laboratory biosafety Guide (Second Edition) 2020 [cited 23 February 2020]. Available from: http://www.nhc.gov.cn/qjjys/s7948/202001/0909555408d 842a58828611dde2e6a26.shtml. 